properties of tungsten metal. Of particular interest to chemists are sections on the extraction of tungsten from its ores, the purification of tungsten compounds, the chemical reactions of the metal, and the adsorption of gases and solids on tungsten surfaces. The third chapter surveys the properties of tungsten compounds including alloys with metals and metalloids. The account of tungsten compounds is totally inadequate. There are no spectroscopic or magnetic data and no structural formulae. T'ungsten hexacarbonyl and its derivatives are dismissed in a page, the octacyano complexes in five lines. The section on halides and oxyhalides contains useful thermodynamic data, but recent important work on their properties and reactions is not mentioned. Tungstenoxygen compounds (oxides, iso- and hetero-polytungstates, tungsten bronzes) are, however, described at length. It is remarkable that a book devoted to a transition metal has no mention of ligand field theory.

The style is lucid and concise except that references are given as authors' names with a date; numerical references would have shortened the book and made it more readable. The index is inadequate. The book as a whole will be useful to metallurgists and others interested in the technology of tungsten and its compounds but, except for a few sections, it will be of little interest to inorganic chemists.

P. C. H. Mitchell

\section{PLUTONIUM AND ITS WORKS}

\section{Plutonium 1965}

Edited by A. E. Kay and M. B. Waldron. (Proceedings of the Third International Conference on Plutonium, London, 1965.) Pp. xv + 1114. (London: Chapman and Hall, 1967. Published for the Institute of Metals.) 252s.

THIs book contains the full text of the sixty-two papers presented at the third international conference held in London by the Institute of Metals in November 1965 and devoted entirely to this rare but most important metal. The conference, which was attended by 337 delegates from fifteen countries, followed two previous ones, also solely concerned with plutonium, which were held in 1957 in America and in 1960 in France. When it is remembered that the conference came only twenty years after the first few grams of plutonium metal were isolated in Los Alamos Laboratory, the number and wide range of papers presented serve to emphasize the vast amount of research which has been devoted to the study of this metal and its compounds in view of its significance in the nuclear industry. Undoubtedly the most important developments in the five years between the second and third conferences were in the ceramic field, as illustrated by the increase in the number of papers from three to twenty-two which deal specifically with the properties and irradiation behaviour of various plutonium-bearing compounds.

In view of the fact that pure plutonium metal can exist in six allotropic forms between room temperature and its melting point, it is not surprising that nine papers specialized in phase transformation studies. These dealt with the effects of purity, alloying, mechanical deformation and pressure on the various possible transformations, with special reference to the equilibrium between the alpha and beta phases. The complexity of the transformations is only too obvious from both the papers and discussion of this subject and, although many important factors have been resolved in the past few years, many problems remain for elucidation.

Ten papers dealt with studies of the physical properties of the metal and its alloys, including four describing work carried out at low temperature. One of the principal aims of these investigations is to provide a better understanding of the band structure of the various plutonium phases and the relative contributions of the $5 \mathrm{f}, 6 \mathrm{~d}$ and $7 \mathrm{~s}$ electrons in providing the high density of states at the Fermi surface. There is a lot of disagreement in interpretation in the field and further work will obviously be required before our understanding of the behaviour of electrons in plutonium and other transuranium metals is improved. It is remarkable that the number of plutonium alloy systems which have been determined either in part or in full must be about equal to that for any other metal. The published data in this field are considerably enhanced. by the seven papers presented at the conference, for more than twenty binary systems were covered as well as the ternary systems $\mathrm{Pu}-\mathrm{Ce}-\mathrm{Fe}$ and $\mathrm{Pu}-\mathrm{Ce}-\mathrm{Ni}$. New data reported by French workers on the solid solubility in plutonium of five metals were derived from solid diffusion studies, and this paper, together with four others on various possible plutonium alloy fuels, was of direct interest to reactor technology. It is interesting to note that in spite of the vast development programme under way on ceramic fuels, some workers, and especially those from the Argonne National Laboratory, still believe that some plutonium alloys may behave sufficiently well when irradiated as to have application in an economic fast reactor. The survey of plutonium metal and its alloys was completed by four papers deseribing mechanical properties, of which two dealt with material in which the delta-phase had been stabilized with 1 weight per cent gallium, and finally three dealing with oxidation behaviour in various atmospheres.

The twenty-two papers concerning ceramic fuels covered a fairly wide range, but the subject matter was almost evenly divided between methods of preparation, phase studies and irradiation behaviour. The materials considered were oxides, carbides, nitrides, phosphides, and sulphides both of plutonium alone and those containing other elements such as uranium or thorium in varying amounts. The compatibility of any fuel with its canning material is extremely important, and so the papers covered equilibria studies between the ceramic phase and stainless steels or refractory metals such as molybdenum. The choice of fuel for a particular reactor depends on many complex factors, and this was well illustrated by the various studies of, for example, irradiation behaviour, which were reported. To assess the relative advantage of any fuel over another requires extremely careful analysis of all the available data, but no clear-cut choice of plutonium fuel emerged from the mass of information presented at the conference.

The editors are to be congratulated on the speed with which the data have been collated, particularly in view of the fact that some authors were permitted to include information that became available after preparation of the preprints. The book obviously contains the most up-to-date information about all aspects of plutonium metal, alloys and compounds of interest to the nuclear industry and will serve as an excellent encyclopaedia to all who are actively engaged in the field. Because of the scientific approach generally adopted in the work described, the book should also appeal to many other scientists and engineers and could act as a stimulus to the application of new thoughts and techniques to problems in other branches of metallurgy and ceramics.

$$
\text { B. W. Мотт }
$$

\section{GOOD BEGINNING}

\section{Advances in Colloid and Interface Science}

Vol. 1, No. 1 (March 1967). Edited by J. T. G. Overbeek, W. Prins and A. C. Zettlemoyer. Published quarterly. Pp. 1-110. Subscription price per volume: 150s.; 75 D.fl.; \$21. (Amsterdam: Elsevier Publishing Company, 1967.) THE appearance of yet another new scientific journal can be welcomed only if it meets certain rigorous specifications 